\title{
Design chosen for nuclear warheads
}

The Lawrence Livermore National Laboratory in California has won a competition to design a new nuclear warhead for the United States. The blueprint could become the basis for the first such weapon produced in more than 20 years.

The Reliable Replacement Warhead (RRW) is intended to replace the 10,000 or so weapons in the current nuclear stockpile, without the need for testing. The United States has maintained a moratorium on the testing of nuclear weapons since 1992 .

The design by the Livermore laboratory and Sandia National Laboratories in New Mexico was chosen over that from the Los Alamos National Laboratory because it was based on previously tested components that would, officials say, provide greater confidence that it could be certified without testing.

The RRW is meant to be a safer and more reliable bomb than the warheads in the current stockpile. For example, it won't use toxic beryllium as today's warheads do, and 'insensitive explosives' will replace conventional ones to trigger the nuclear reaction, lowering the risk that the bomb will go off accidentally. "It's not about starting a new arms race," says Steve Henry, deputy assistant to the secretary of defence for nuclear matters. "The new design gives us an opportunity to move on from methods and techniques used during the cold war."

But critics note that the language the agency has used to defend the RRW programme has shifted since discussions began in earnest in 2005 .

At first, the main argument "The new design gives us an opportunity to move on from methods used during the cold war."

ing safety and security," says Robert Nelson, a physicist at the Union of Concerned Scientists' Global Security Program in Washington DC.

Others argue that if the RRW project goes ahead, it could actually increase pressure to resume testing. One of its goals is to keep generations of engineers and scientists trained in in support of the RRW was that the current stockpile might become unreliable if radioactivity leaking from the plutonium pit damaged the surrounding metal. But research released last November showed that the current generation of weapons will last for $85-100$ years (see Nature 444, 660-661; 2006). "Now if you read their press statements, it's all about improv- nuclear-weapons skills, which would require designing and redesigning the warheads. Philip Coyle, senior adviser to the Center for Defense Information in Washington DC, says that he finds it hard to see how the cumulative effects of successive modifications could be certified without a return to testing.

But for the programme to move forward, the costs and a production plan will need to be agreed by Congress, some key members of which have already expressed their opposition to the project.

Lucy Odling-Smee 